\title{
Dietary Habits in Patients with Ulcerative Colitis-Cause of Nutrient Deficiency?
}

\author{
U. Bach1, H. N. Jensen², H. H. Rasmussen ${ }^{3,4}$, J. Fallingborg5, M. Holst ${ }^{3,6}$ \\ ${ }^{1}$ Department of Cardiology, Center for Cardiovascular Research, Aalborg University Hospital, Aalborg, Denmark \\ ${ }^{2}$ Department of Nutrition, Regional Hospital West Jutland, Holstebro, Denmark \\ ${ }^{3}$ Centre for Nutrition and Bowel Disease, Aalborg University Hospital, Aalborg, Denmark \\ ${ }^{4}$ Faculty of Health, Aalborg University, Aalborg, Denmark \\ ${ }^{5}$ Department of Gastroenterology, Aalborg University Hospital, Aalborg, Denmark \\ ${ }^{6}$ Institute for Planning, Aalborg University, Aalborg, Denmark \\ Email: u.bach@rn.dk
}

Received 12 August 2014; revised 6 September 2014; accepted 18 September 2014

Copyright (C) 2014 by authors and Scientific Research Publishing Inc.

This work is licensed under the Creative Commons Attribution International License (CC BY). http://creativecommons.org/licenses/by/4.0/

(c) (i) Open Access

\begin{abstract}
Background: Up to $60 \%$ of patients with ulcerative colitis are seen with nutrient deficiency; however, no specific diet is recommended. The aim of this study was to obtain knowledge on whether restriction or addition of specific food items might contribute to malnutrition in these patients. Methods: A qualitative semi-structured interview study of outpatient clinic patients with ulcerative colitis aimed to investigate preferences for or avoidance of specific food items related to abdominal symptoms. Results: The study included 25 patients (12 M, 13 F), average age 46.7 years (SD 15.6). Duration of disease ranged from 1 to 35 years. Restriction of food items was mainly due to discomfort associated with bowel symptoms, e.g. diarrhoea caused by sugar, dairies, alcohol, spices, red meat, and bread. Restrictions were based mainly on personal experience rather than professional guidance or knowledge search. Addition of specific food items most often included vitamin supplements. Only $\mathbf{2 0 \%}$ took supplementary calcium, although many restricted the consumption of dairies from their diet. Conclusion: Many patients with ulcerative colitis restrict consumption of dairy products from their diet. This may lead to calcium deficiency. No other dietary restrictions, which might explain specific nutrient deficiencies, were identified.
\end{abstract}

\section{Keywords}

Ulcerative Colitis, Malnutrition, Abdominal Symptoms, Restriction, Calcium Deficiency, Diet

\section{Introduction}

Between 25\% and 60\% of ulcerative colitis (UC) patients are malnourished [1] [2]. Osteoporosis is seen in 3\% -

How to cite this paper: Bach, U., Jensen, H.N., Rasmussen, H.H., Fallingborg, J. and Holst, M. (2014) Dietary Habits in Patients with Ulcerative Colitis-Cause of Nutrient Deficiency? Food and Nutrition Sciences, 5, 1945-1950. 
$58 \%$ of the patients, caused by various reasons [3]. Deficiencies of $\mathrm{B}_{12}$, zinc, vitamin $\mathrm{D}$, and iron are also seen in $5 \%, 10 \%, 35 \%$, and $55 \%$, respectively, of the patients [4]. Several studies have examined dietary recommendations for patients with UC, but the results are inconclusive. However, current recommendations are that the patients, as far as possible, should eat a varied normal diet [3].

Surveys and experience of work with the patient group indicate that patients with UC avoid food or even whole food groups in order to avoid exacerbation [1] [2].

The purpose of this study was to generate knowledge about eating habits including restriction or addition of food items and supplements in patients with UC and evaluate if potential restrictions can be the causes of nutritional deficiencies.

The Department of Gastroenterology, Aalborg University Hospital, receives 8078 patients annually of whom 1227 patients have UC (2010 figures).

\section{Methods}

\subsection{Participants}

Patients with UC who consulted specialists at the outpatient clinic at Aalborg University Hospital in FebruaryMarch 2012 were invited to participate in the study. Patients with duration of disease longer than six months were asked to participate in the study and were included regardless of disease activity.

\subsection{Study Method}

A semi-structured qualitative interview based on an interview guide [5] [6] was used to allow an in-depth exploration of patient experience with diet in relation to UC. The interview guide was used in an unstructured format to guide the patient and the interviewer through the interview.

The focus of the interview guide was from where the patients had knowledge of their restriction or addition of specific food items, and their experience thereof. They were also asked about any specific situations where a change in diet had occurred. Finally, they were asked about experience with dietary supplements including herbal medicine. The following food groups were included in the interview guide: alcohol, dairy products, meat, cereals, vegetables, and supplements, e.g. fish oil, probiotics, protein powder, ispaghula husks, and aloe vera. Each interview was tape recorded and transcribed. Inclusion continued until data saturation was reached.

\subsection{Analysis}

A structured analysis of the transcribed interviews was conducted. Patterns of meaning from within and amongst the interview were observed, and themes were identified. The data was collated and organised initially under headings corresponding to the identified themes.

The quotations outlined beneath in italics represent these patterns. The text in brackets in the quotations is the interviewer's additions to clarify the meaning of the quotations.

\subsection{Ethical Considerations}

Prior to inclusion, the patients were orally informed about the project and were offered written information.

When having decided to participate, an appointment was made on when and where the interview was to take place. The study was conducted according to the Declaration of Helsinki.

\section{Results and Discussion}

A total of 25 patients were included (12 M and $13 \mathrm{~F}$ ), average age 46.7 years (SD 15.6). Duration of disease ranged from 1 to 35 years, average duration 15 years (SD 13). Inclusion continued until no further knowledge was obtained during three interviews in a row, thus reaching data saturation. The interviews lasted from 5.37 to 44.31 minutes.

More than half $(60 \%)$ of the participants did not drink milk at all, or had a reduced intake. The reasons for this were various. Some did not like it: "I restrict milk, but I also did so before (getting UC)", whereas others restricted milk because of symptoms, either deliberately "If I eat dairy products, I get diarrhoea after 1 to 3 days" or unconsciously "unconsciously I have restricted them (dairy products), because my stomach did not work well 
after consuming them". None of the participants mentioned lactose intolerance as a reason for restriction.

Only one third of the participants, who did not drink milk or had a reduced intake of milk, took calcium supplements. Data are given in Table 1.

Another food that was often omitted was bread, and more than half (60\%) omitted bread in one form or another. However, it differs whether it was white bread or fibre-rich bread, including rye bread, that was omitted, and the reasons for opting out were different. Intake of fibre-rich bread types were most commonly associated with diarrhoea and abdominal pain, whereas white bread was associated with constipation and bloating: "I cannot eat all types of white bread. Preferably, it should contain some fibres-to ensure that nothing goes wrong, e.g. bloating". "White bread, I connect that with everything coming to a halt (stomach and intestines)... I also have a tendency to become bloated and feel pain in the stomach when eating it".

The intake of meat was omitted entirely or partly by every other participant (48\%), mainly on the basis of symptoms experienced by ingestion. Red meat (not cooked thoroughly), smoked meat, fat or beef is omitted, while intake of lighter meat like fish, chicken, and turkey was generally not a nuisance, "Preferably, I avoid beef. I eat mainly chicken or fish. My stomach is easier to manage. I get more uncomfortable when I have eaten beef'.

In general, the participants expressed trouble ingesting fatty food. When asked in detail about fatty foods, different food items are mentioned by different participants. Chips, creamed potatoes, fat gravy, fatty meat, or meat coated in breadcrumbs, fried meat, deep fried food, and cake with whipped cream are mentioned. Mainly, fatty food is consumed on special occasions.

Up to one third also had problems with strong and spicy food, especially chilli, and ingestion of this was associated with abdominal pain and diarrhoea.

Almost half (48\%) of the participants did not drink alcohol or at least only in limited quantities. Of these, more than half (8/12) got symptoms at intake: "Alcohol is not very good; I just get such a sore stomach", whereas others did not drink alcohol due to other reasons "I do not drink, but I've never done, so it has nothing to do with this (the UC)".

There was no consensus when participants talked about their experience with vegetables. Some indicated that the vegetables should ideally be boiled while others did not tolerate cabbage, leeks, onions, carrots, and corn. However, the vast majority ate all vegetables regardless of cooking form.

Sugar and candy were given as the cause of abdominal pain, flatulence, and/or diarrhoea in almost $25 \%$ of the patients (7/25): "Candy, all types of cake (trigger to the stomach), and, of course soft drinks".

Virtually no participants added specific foods or supplements with the aim of relieving symptoms. A few believe that yogurt was good for the stomach.

About one third of the participants tried the psyllium seeds/ispaghula husks. Half of them experienced a positive effect of ispaghula husks, but the rest found that ispaghula husks either worsened, or had no effect on, symptoms. In addition, the participants only had limited experience with alternative diets such as for instance a gluten-free diet.

Nearly half (40\%) consumed a daily vitamin supplement, and a few consumed vitamin D, fish oils, and other supplements. Most dietary supplements were not consumed because of the UC, but e.g. because of joint pain (fish oil) or merely to improve general health. Data are given in Table 2.

Table 1. Number of participants who restricts different food items.

\begin{tabular}{cc}
\hline Restriction of & Number of participants \\
\hline Dairy products & $60 \%$ of which $33 \%$ take calcium supplements \\
Bread (white or coarse) & $60 \%$ \\
Meat & $48 \%$ \\
Spicy foods & $30 \%$ \\
Alcohol (often red wine) & $48 \%$ \\
Sugar/candy & $28 \%$ \\
Vegetables & No consensus \\
\hline
\end{tabular}


Table 2. Number of participants who adds dietary supplements.

\begin{tabular}{cc}
\hline Addition of & Number of participants \\
\hline Ispaghula HUSK & $33 \%$ \\
Multivitamin & $40 \%$ \\
\hline
\end{tabular}

Restriction of food was mainly based on personal experience, but also the Internet and magazines had an impact: "I think you pick up bits from what you read and who you talk to, and also how you react on different foods". Many patients felled that they did not receive information on diet from the hospital or their general practitioner, and they therefore searched for information themselves.

Many are of the perception that diet plays a vital role as they were experiencing symptoms from the gastrointestinal tract when consuming specific food. These symptoms were related with UC.

Many used the word "tolerate" when they talked about foods that caused symptoms-they did not tolerate such food. One participant had been diagnosed with milk allergy, but otherwise the participants appeared to have no food allergies.

The participants included in this study were heterogeneous according to disease duration and disease activity or not. This was not believed to influence the knowledge gained on the eating habits of the patients since all were asked if there were any differences between having flare-ups and being in remission.

We conducted qualitative interviews based on an interview guide. Because of the applied method, we were not able to generalise, but data saturation ensured that the reader was provided with a fair impression of eating habits among the selected population. The qualitative interviews also proved to be valid in this study because of specific data that could not be obtained e.g. by means of a survey merely. Several times a participant indicated that he/she could eat everything, but when asked in details, it frequently appeared that the person still left some food items out.

There may be response bias due to the participants facing healthcare professionals and talking about their diet. It has been shown that there is a tendency to under-report the unhealthy and over-report the healthy food items [7] and, therefore, one cannot rule out that participants e.g. indicated that they did not eat white bread because they know it was better to eat whole meal bread. It was shown that up to $80 \%$ of patients with UC also have irritable bowel syndrome (IBS) [8], and therefore it might be difficult to distinguish whether symptoms from intake of food items were caused by IBS, CU, or other factors. Several participants showed symptoms before they were diagnosed with UC, which helps support the hypothesis that the symptoms do not always come from UC.

More than half of the participants did not drink milk or only drank limited amounts, which was a significantly less intake compared to Danes' intake of dairy products in general [9]. A low calcium intake may inhibit the formation of bone during growth and cause bone loss [10], and osteoporosis is seen within the patient group (3\% - 58\%). Hence, it seems that patients with UC are at greater risk of developing osteoporosis than the general population [3]. At the same time, few of the participants who had limited or no intake of milk took an additional calcium supplement, thus making this an important area of focus.

In addition, it is envisioned that there could be a malabsorption of calcium during flare-ups due to diarrhoea.

An assessment of intake of milk is not sufficient, and patients' intake of fermented milk products and cheese should also be included. At the same time, there should also be a focus on patients' vitamin D status in relation to calcium absorption [10], all of which will form the basis for assessing the patient group's calcium status, including the assessment of the necessity of a calcium supplement.

Several participants omitted red and/or fatty meats and instead prioritised lean meats from chicken and fish. Mostly, these meats were omitted because of symptoms at intake, but the mechanism causing these symptoms was not clear. An observational study found that intake of meat, protein, and alcohol was associated with greater risk of flare-ups, and this was due to the contents of sulphur or sulphate. However, this was only an observation and thus did not prove that the relationship was as such or because of the substances [11]. Restriction of both dairy products and meat, or a limited intake of both, could potentially lead to protein deficiency. This is probably something one should be aware of.

There was no consensus about the intake of vegetables. However, some participants indicated the "stringy vegetables" such as cabbage, leeks, and onions to be causes of symptoms. Participants, however, omitted these based on experience rather than what they had been told. Another reason might be that the participants in this study had a high age, and their intake of vegetables might be lower than that of young participants. 
It could be seen as positive that several participants omitted white bread in favour of the coarser types. But there were also several patients who, because of symptoms, did not eat coarser kinds of bread including rye bread, and therefore these patients might conceivably have a lower intake of dietary fibre. Dietary fibre might cause increased formation of gas in the intestine, causing symptoms such as flatulence and abdominal pain [10].

The fibre product of ispaghula husks are recommended in the medical context and by the Danish Association of Clinical Dieticians [12] to patients with diarrhoea and constipation, including patients with UC flare-ups. In this study, half of those who had tried ispaghula husks had no positive experiences with the product.

Several participants indicated that fatty foods cause problems, and that the discomfort derived from many different fatty products, which are mainly consumed on special occasions. Several participants addressed this aspect, "Maybe the indisposition comes from the body not used to getting it". This was also indicated by an increased rate of admission with abdominal disorders during Christmas days compared to non-Christmas days [13].

Based on experience, many restricted red and fatty meats, fatty products, and alcohol, and instead prioritised lean meat from chicken and fish and lighter products. These products were said to have a positive influence on patients' health status and were consistent with general dietary guidelines that patients were advised to follow [14].

At Aalborg University Hospital, all newly diagnosed patients with UC were offered to participate in a patient school where participants learn about diet and UC. It must be assumed that some of those interviewed have not undergone patient education since they were diagnosed many years ago, which could be the reason why some patients thought they did not gain knowledge within the hospital service. Patients, who were hospitalised and were at nutritional risk or, patients in the outpatient clinic, who had been shown to have problems with dietary intake, were offered individual counselling by a clinical dietician. The present study did not consider the presence of clinical evidence to alter this practice.

This study has gained knowledge on what, when and why patients with UC restrict food items from their usual diet. Especially, milk, bread, alcohol, red meat, and fatty foods are omitted from their diet, i.e. this study indicated that restriction of food followed the general recommendations for dietary intake. Reduced consumption of milk products might give rise to calcium deficiency if not replaced, and protein deficiency if also meat and pulses are omitted. In addition, the study did not provide knowledge on possible causes of other nutritional deficiencies.

\section{Conclusion}

From the therapist's hand, an increased focus should be on the restriction of milk and dairy products in this patient group and a calcium supplement may be necessary for some. In any case, patients should be tested for lactose intolerance before milk is restricted.

\section{Conflicts of Interest}

None declared.

\section{Source of Funding and Authorship}

The first, second and last authors contributed to the research proposal development, data analysis, and manuscript preparation. Data was collected by the first and second authors. All authors critically reviewed the manuscript and approved the final version submitted for publication.

\section{References}

[1] Sethi, A.K. and Sarna, S.K. (1991) Colonic Motor Response to a Meal in Acute Colitis. Gastroenterology, 101, 15371546.

[2] Hoffmann, J.C. (2010) Crohn's Disease and Ulcerative Colitis: In Young Women Often Misdiagnosed as Anorexia. MMW Fortschritte der Medizin, 152, 34.

[3] Lomer, M.C.E. (2011) Dietary and Nutritional Considerations for Inflammatory Bowel Disease. Proceedings of the Nutrition Society, 70, 329-335. http://dx.doi.org/10.1017/S0029665111000097

[4] Lochs, H., Dejong, C., Hammarqvist, F., et al. (2006) ESPEN Guidelines on Enteral Nutrition: Gastroenterology. 
Clinical Nutrition, 25, 260-274. http://dx.doi.org/10.1016/j.clnu.2006.01.007

[5] Kvale, S. (1997) Interview. En introduktion til det kvalitative forskningsinterview. Hans Reitzel, København.

[6] Holst, M., Rasmussen, H.H. and Laursen, B.S. (2011) Can the Patient Perspective Contribute to Quality of Nutritional Care? Scandinavian Journal of Caring Sciences, 25, 176-184. http://dx.doi.org/10.1111/j.1471-6712.2010.00808.X

[7] Gibson, R.S. (2005) Principles of Nutritional Assessment. 2nd Edition, Oxford University Press Inc., New York.

[8] Simrén, M., Axelsson, J., Gillberg, R., et al. (2002) Quality of Life in Inflammatory Bowel Disease in Remission: The Impact of IBS-Like Symptoms and Associated Psychological Factors. American Journal of Gastroenterology, 97, 389-396. http://dx.doi.org/10.1111/j.1572-0241.2002.05475.x

[9] DTU Fødevareinstituttet (2012) Danskernes Kostvaner 2003-2008. Søborg.

[10] Lupton, J.R., Trumbo, P.R. and Heaney, R.P. (2006) Modern Nutrition in Health and Disease. In: Shils, M.E., Shike, M., Ross, A.C., Caballero, B. and Cousins, R.J., Eds., 10th Edition, Lippincott Williams \& Wilkins, Baltimore.

[11] Jowett, S.L., Seal, C.J., Pearce, M.S., et al. (2004) Influence of Dietary Factors on the Clinical Course of Ulcerative Colitis: A Prospective Cohort Study. Gut, 53, 1479-1484. http://dx.doi.org/10.1136/gut.2003.024828

[12] Foreningen af Kliniske Diætister (2011) Diætbehandling af voksne patienter med kronisk inflammatorisk tarmsygdom (IBD): Morbus Crohn og Colitis Ulcerosa (UC). Foreningen af kliniske Diætister.

[13] Ramanathan, R., Brabrand, M., Folkestad, L., et al. (2011) A Peaceful Christmas Eve at the Hospital. Ugeskr Laeger, 173, 3178-3181.

[14] Nordic Council (2004) Nordic Nutrition Recommendations 2004. 4th Edition, Nordic Council of Ministers, Copenhagen. 
Scientific Research Publishing (SCIRP) is one of the largest Open Access journal publishers. It is currently publishing more than 200 open access, online, peer-reviewed journals covering a wide range of academic disciplines. SCIRP serves the worldwide academic communities and contributes to the progress and application of science with its publication.

Other selected journals from SCIRP are listed as below. Submit your manuscript to us via either submit@scirp.org or Online Submission Portal.
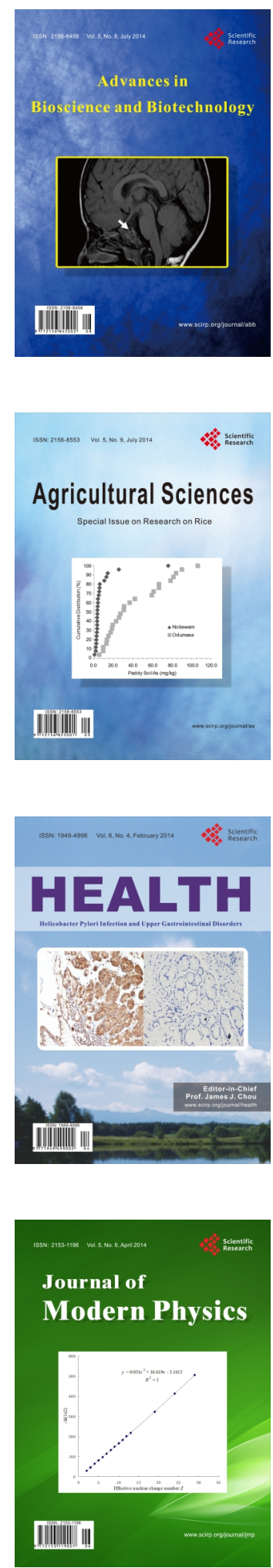
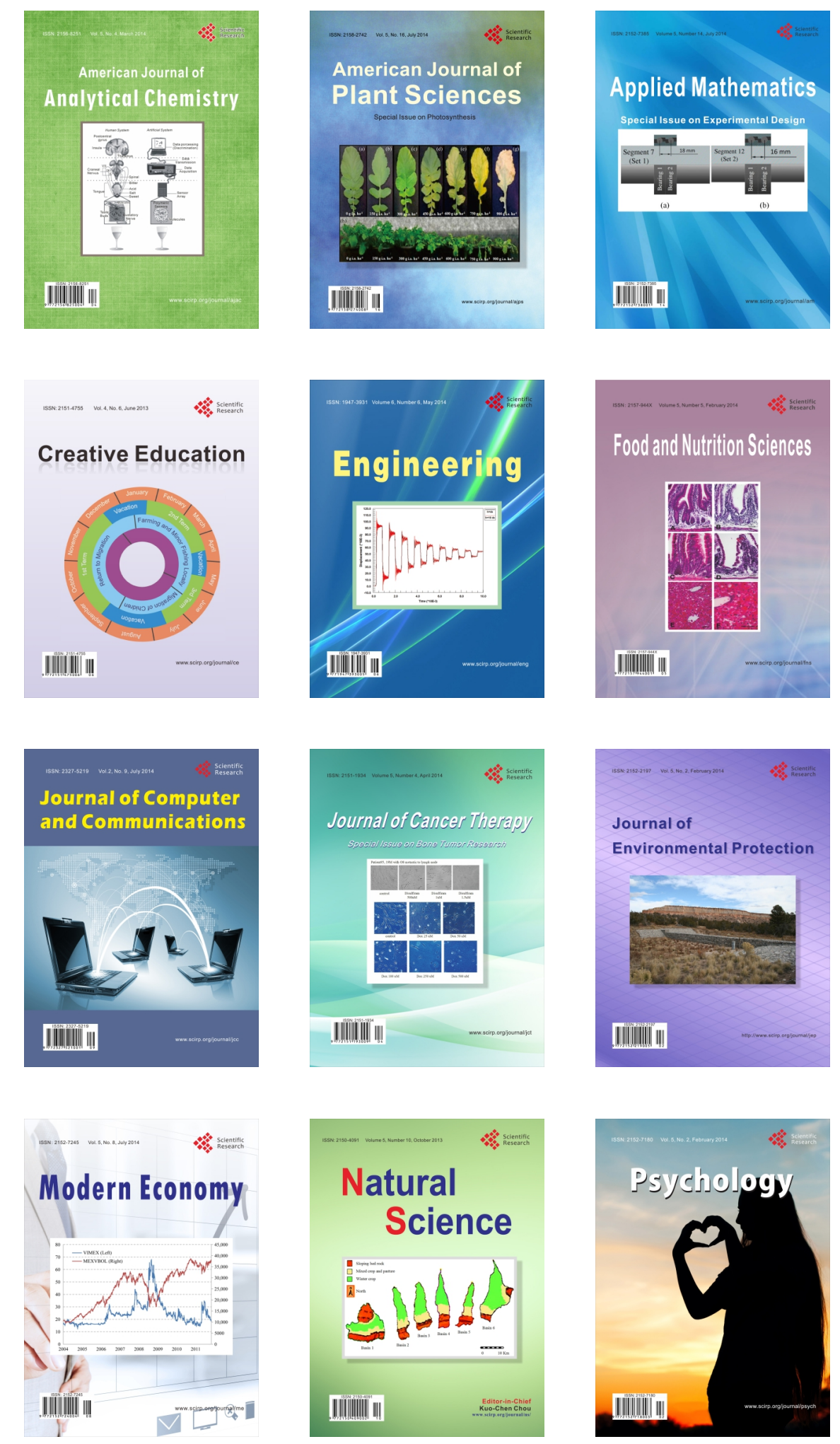